\title{
Coronary spasm that caused non-ST elevation myocardial infarction appeared in cath lab due to vasovagal reaction
}

\author{
Miodrag Jovan Sreckovic, Nikola Jagic, Vladimir Zdravkovic, Dusan Nikolic, Mladen Tasic, \\ Ana Maksimovic Sreckovic, Vladimir Miloradovic \\ Department of Interventional Cardiology, Clinical Center Kragujevac, Kragujevac, Serbia
}

Postep Kardiol Inter 2014; 10, 2 (36): 138-140

DOI: $10.5114 / p w k i .2014 .43525$

\begin{abstract}
A bstract
Coronary artery spasm is sometimes an unrecognized cause of myocardial ischemia. Myocardial ischemia is not always a product of fixed stenosis; it can also be induced by dynamic, transient stenosis. The angiogram represents the current state of vasculature at the time of examination and absence of stenosis does not mean disease absence. We present a case of right coronary artery spasm that caused non-ST elevation myocardial infarction and arrhythmias and was induced again in the cath lab due to vasovagal reaction.
\end{abstract}

Key words: coronary artery spasm, vasovagal reaction, non-ST elevation myocardial infarction.

\section{Case report}

A female patient, aged 71 years, was admitted to the emergency room due to palpitations, increasing shortness of breath, and nausea. She had already experienced similar, less intense symptoms before. Previous medical history: hypertension, dyslipidemia, smoker, irregularly takes medications. Electrocardiogram (ECG) on admission revealed rapid atrial fibrillation, heart rate $(H R)$ about

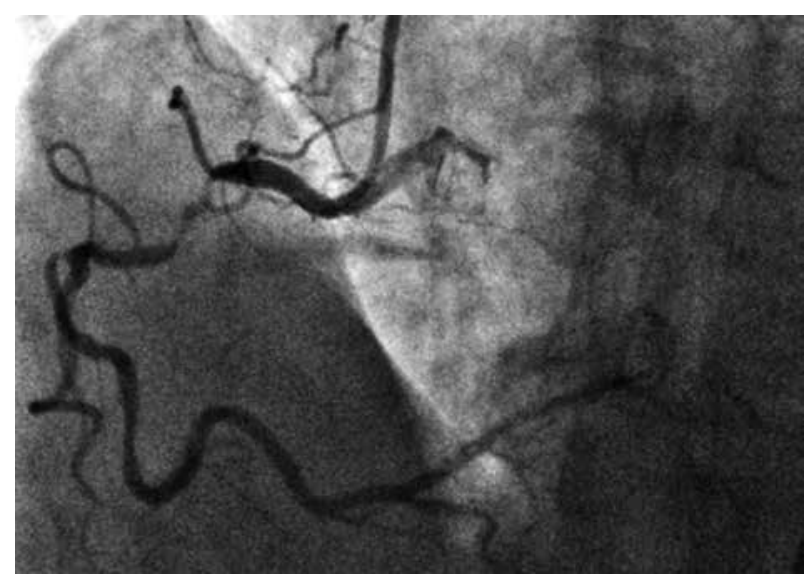

Figure 1. Coronary spasm produces subocclusive lesion in mid RCA
$130 \mathrm{bpm}$, and left bundle branch block (LBBB). She brought some old ECG strips, sinus rhythm, without LBBB. Laboratory findings indicated increased values of $\mathrm{Tnl} 0.368 \mathrm{ng} /$ $\mathrm{ml}$, glycemia $8.5 \mathrm{mmol} / \mathrm{l}$, cholesterol $5.87 \mathrm{mmol} / \mathrm{l}$, LDL $3.85 \mathrm{mmol} / \mathrm{l}$, D-dimer $798.31 \mathrm{ng} / \mathrm{ml}$. Chest $X$ ray showed signs of incipient consolidation on the left side. Computed tomography pulmonary angiography was performed and did not show signs of embolism. During observation in the coronary unit the patient was in sinus rhythm, but episodes of transient LBBB and rapid atrial fibrillation with premature supraventricular contractions were recorded. Before coronarography the patient was nervous, blood pressure (BP) was 170/90 mm Hg, ECG showed sinus rhythm $90 \mathrm{bpm}$. After the sheath was introduced into the right femoral artery, a severe vasovagal reaction occurred. Blood pressure dropped to $70 / 40 \mathrm{~mm} \mathrm{Hg}$, bradycardia with heart rate $38 \mathrm{bpm}$, nausea. Saline infusion and an intravenous bolus of atropine $1 \mathrm{mg}$ were administered. After a while, premature ventricular contractions and transient LBBB appeared; the patient reported retrosternal pain. When systolic pressure rose above $100 \mathrm{~mm} \mathrm{Hg}$, angiography was performed. The left coronary system was without angiographically severe stenosis. Angiography of the right coronary artery (RCA) revealed a subocclusive lesion in the medial part, and slow flow in the distal part of the artery -

Corresponding author:

Miodrag Jovan Sreckovic MD, Department of Interventional Cardiology, Clinical Center Kragujevac, 5/4 Kumanovska St, 34000 Kragujevac, Serbia, phone: 381693371777, e-mail: sreckovic7@gmail.com

Received: 17.12.2013, accepted: 11.04.2014. 
TIMI II (Figure 1). Since BP was $115 / 80 \mathrm{~mm} \mathrm{Hg}$, the operator wanted to administer $50 \mu \mathrm{g}$ of intracoronary nitroglycerin (NTG), to observe the true vessel diameter for stent sizing. After NTG was administered, the subocclusive lesion disappeared, only $30-40 \%$ of residual stenosis was present, TIMI III flow in RCA (Figure 2). Coronary stenting was deferred and we opted for medical treatment.

\section{Discussion}

The possible role of parasympathetic nervous system (PSNS) in the pathogenesis of coronary artery spasm (CAS) was investigated because it is known that CAS occurred most often when patients were at rest, and was usually not induced by exercise in the daytime [1]. Yasue et al. [2] demonstrated that CAS can be induced by subcutaneous injection of methacholine, an analogue of acetylcholine (Ach), and that the attack can be suppressed by atropine in some patients with variant angina. Ludmer et al. [3] concluded that paradoxical vasoconstriction induced by Ach occurs early as well as late in the course of coronary atherosclerosis. They suggested that the vascular response to Ach may represent a defect in endothelial vasodilator function, and may be important in the pathogenesis of coronary vasospasm. Ach exerting its effect via muscarinic receptors can induce vasoconstriction by acting on medial smooth muscle cells, and vasodilation mediated by endothelial release of endothelium-derived relaxing factor. In human coronary arteries, several studies have found either contractile or relaxant responses to Ach, with contractile responses seen more often in coronary arteries with endothelial dysfunction secondary to atherosclerosis or old age, where parasympathetic stimulation could be of pathophysiological importance [4]. Egashira et al. [5] demonstrated that nitric oxide (NO) was not decreased at the spastic sites of the coronary arteries; they pointed to additional mechanisms, such as enhanced phospholipase $C$ enzyme activity inducing focal smooth muscle cell hypersensitivity in variant angina patients. Motoyama et al. [6] discovered that plasma levels of vitamin $E$ and another antioxidant were low in patients with CAS. Subsequently, Ito et al. [7] showed that polymorphisms of Glu298Asp in exon 7 and T-786C in the 5'-flanking region of the endothelial nitric oxide synthase (eNOS) gene and paraoxonase gene Gln192Arg (Q192R) polymorphism were significantly associated with CVS. Paraoxonase I gene has an antioxidant effect and CVS occurs more often in cigarette smokers [8]. Masumoto et al. [9] investigated the mechanism of vascular smooth muscle contraction, and discovered that GTPase RhoA and its downstream effector, ROCK/Rho-kinase, inhibit myosin light chain phosphatase and intensify myosin light chain phosphorylation and $\mathrm{Ca}^{2+}$ sensitization in response to vasoconstrictor stimuli. The ROCK inhibitor fasudil diminished coronary artery spasm in humans. Sauzeau et al.

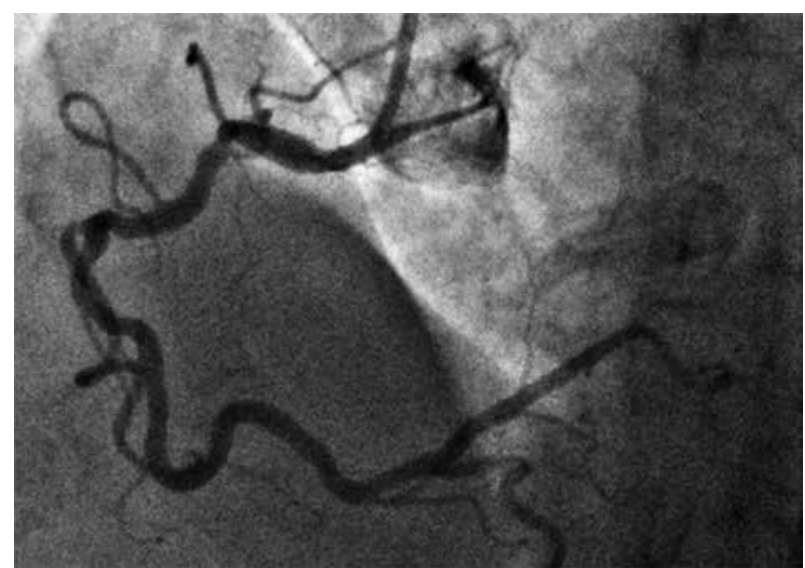

Figure 2. After NTG was administered, the subocclusive lesion disappeared

[10] found an association between decreased endothelial nitric oxide activity and increase of RhoA/ROCK activity in coronary arteries.

\section{Conclusions}

Awareness and knowledge of CAS and its pathophysiology has great importance for cardiologists who deal with acute coronary syndrome (ACS) patients. Most attacks are associated with ST-segment depression rather than ST-segment elevation. Angiographically normal coronary arteries occur in $25 \%$ of patients with ACS [11]. The pharmacologic provocation testing of CAS is recommended in patients with recurrent episodes of apparent ischemic chest pain at rest who have normal or mildly abnormal coronary angiograms, with no clinical observations substantiating the diagnosis of variant angina, i.e. ST-segment elevation during pain [12]. Calcium-channel blockers seem to be the established therapy for CAS, and the decrease in frequency of variant angina is attributed to the widespread use of these drugs. Long-acting nitrates were also found to be efficient, and their vasodilatory effect may be additive to calcium antagonists. Response to $\beta$-blockade varies: in some, particularly in those with associated fixed lesions, a reduction in the frequency of exertion-induced angina is observed, but in others these drugs may be detrimental [13]. Magnesium deficiency is a possible factor contributing to CAS, and Teragawa et al. [14] suggested that its long-term supplementation might also have a preventive effect. Suppression of acetylcholine-induced CAS through the addition of a statin to conventional calcium-channel blocker therapy was reported by Yasue et al. [15]; the purported mechanism is inhibition of the RhoA-associated kinase pathway.

\section{References}

1. Araki H, Koiwaya Y, Nakagaki O, Nakamura M. Diurnal distribution of ST segment elevation and related arrhythmias in patients 
with variant angina: a study by ambulatory ECG monitoring. Circulation 1983; 67: 995.

2. Yasue H, Touyama M, Tanaka S, Akiyama F. Prinzmetal's angina: atropine suppression. Ann Intern Med 1974; 80: 553.

3. Ludmer PL, Selwyn AP, Shook TL, et al. Paradoxical vasoconstriction induced by acetylcholine in atherosclerotic coronary arteries. N Engl J Med 1986; 315: 1046-51.

4. Saetrum Opgaard O, Gulbenkian S, Edvinsson L. Innervation and effects of vasoactive substances in the coronary circulation. Eur Heart J 1997; 18: 1556-68.

5. Egashira K, Inou T, Yamada A, et al. Preserved endothelium-dependent vasodilation at the vasospastic site in patients with variant angina. J Clin Invest 1992; 89: 1047-52.

6. Motoyama T, Kawano H, Kugiyama K, et al. Vitamin E administration improves impairment of endothelium-dependent vasodilation in patients with coronary spastic angina. J Am Coll Cardiol 1998; 32: 1672-9.

7. Ito T, Yasue H, Yoshimura M, et al. Paraoxonase gene Gln192Arg (Q192R) polymorphism is associated with coronary artery spasm. Hum Genet 2002; 110: 89-94.

8. Hung MJ, Hung MY, Cheng CW, et al. Comparison of clinical characteristics and prognosis in Taiwanese patients with coronary vasospastic angina pectoris without significant fixed coronary artery disease versus patients with significant fixed coronary artery disease and either stable angina pectoris or acute coronary syndromes. Am J Med Sci 2007; 334: 160-7.

9. Masumoto A, Mohri M, Shimokawa H, et al. Suppression of coronary artery spasm by the Rho-kinase inhibitor fasudil in patients with vasospastic angina. Circulation 2002; 105: 1545-7.

10. Sauzeau V, Rolli-Derkinderen M, Marionneau C, et al. RhoA expression is controlled by nitric oxide through cGMP-dependent protein kinase activation. J Biol Chem 2003; 278: 9472-80.

11. Ong P, Athanasiadis A, Hill S, et al. Coronary artery spasm as a frequent cause of acute coronary syndrome: the CASPAR (Coronary Artery Spasm in Patients With Acute Coronary Syndrome) Study. U J Am Coll Cardiol 2008; 52; 523-7.

12. Scanlon PJ, Faxon DP, Audet AM, et al. ACC/AHA guidelines for coronary angiography. A report of the American College of Cardiology/American Heart Association Task Force on practice guidelines (Committee on Coronary Angiography). Developed in collaboration with the Society for Cardiac Angiography and Interventions. J Am Coll Cardiol 1999; 33: 1756-824.

13. Cannon CP, Braunwald E. Unstable angina and non-ST elevation myocardial infarction. In: Braunwald's heart disease. Libby $\mathrm{P}$, Bonow RO, Mann DL, Zipes DP (eds.). $8^{\text {th }}$ ed. Saunders Elsevier, Philadelphia 2008; 1319-51.

14. Teragawa $H$, Kato $M$, Yamagata $T$, et al. The preventive effect of magnesium on coronary spasm in patients with vasospastic angina. Chest 2000; 118: 1690-5.

15. Yasue H, Mizuno Y, Harada E, et al.; the SCAST (Statin and Coronary Artery Spasm Trial) Investigators. Effects of a 3-hydroxy-3-methylglutaryl coenzyme A reductase inhibitor, fluvastatin, on coronary spasm after withdrawal of calcium-channel blockers. J Am Coll Cardiol 2008; 51: 1742-8. 